\title{
In Vitro Antibiotic Activity of Red Shallot (Allium ascalonicum), Mulberry (Morus indica), and Marigold (Tagetes erecta) Extracts against Streptococcus pyogenes
}

\author{
Tanawadee Mekvimol' ${ }^{1}$ Chayanit Chaipunna1, Gannika Poonthong1 ${ }^{1}$, and Natapol Pumipuntu ${ }^{1,2^{*}}$ \\ ${ }^{I}$ One Health Research Unit, Faculty of Veterinary Sciences, Mahasarakham University, Maha Sarakham, Thailand \\ ${ }^{2}$ Faculty of Veterinary Sciences, Mahasarakham University, Maha Sarakham, Thailand \\ *Corresponding author's Email: film.natapol@gmail.com; (DORCiD: 0000-0002-0612-9847
}

\begin{abstract}
Bacterial infection is a major global health concern. One of the critical problems is the widespread of antimicrobialresistant bacteria from inappropriate and prolonged use of antimicrobial agents in both humans and animals. Plant extracts might afford the chance to replace antibiotic drugs and reduce the emerging of antimicrobial-resistant bacteria. This study aimed to examine the antibiotic activity of ethanolic crude extracts of some Thai medicinal plants grouping in their parts as whole onions of red shallot (Allium ascalonicum), petals of marigold (Tagetes erecta), mulberry leaves, and root barks (Morus indica) to inhibit the growth of Streptococcus pyogenes. The antibiotic activities of the crude extract of three Thai medicinal plants using absolute ethanol were trialed against Streptococcus pyogenes using the disk diffusion method. Erythromycin and Ceftriaxone discs were chosen to be positive control standards as the representative of antibiotic drugs. Each dried plant extracts was prepared to test the inhibition with a concentration at 25,50 , and $75 \mathrm{mg} / \mathrm{mL}$ stock solution. The results showed that three groups from all testing groups of Thai medicinal plant extracts had the potential of antibiotic activity against $S$. pyogenes. The highest antibiotic activity against $S$. pyogenes was detected from whole onion extract red shallot followed by the extract of the mulberry leaves and root barks of mulberry strain Nakhon Ratchasima 60 (Nak 60) while the extract of marigold petal did not present antibiotic activity. The results revealed that crude extract of those two Thai medicinal plants, including red shallot and mulberry, had antibiotic activity against bacterial growth of $S$. pyogenes in the experiment and these medical Thai plants had potential benefits for developing as alternative treatment agents for $S$. pyogenes infections in both humans and animals in the future.
\end{abstract}

Keywords: Antibiotic activity, Ethanolic crude extract, Thai medicinal plants, Streptococcus pyogenes

\section{INTRODUCTION}

Streptococcus pyogenes (S. pyogenes) is known as an important Gram-positive bacteria which display oxidase negative, catalase-negative, and $\beta$-hemolytic on blood agar. It is a facultative anaerobe bacteria that usually grows in 5-10\% carbon dioxide and forms colonies on blood agar. It is grouped as Group A Streptococci (GAS) by Lancefield serological grouping system (Spellerberg, 2016). In humans, S. pyogenes normally colonizes in the throat, skin epithelial surfaces, anus, genital mucosa, and pharynx (Cunningham, 2000), while it was reported to be found in the eye discharge of a dog with conjunctivitis, feces of a dog with colitis, free-living European hedgehog, free-ranging non-human primates and bovine mastitis (Vela et al., 2017). However, the spread of the bacteria to typically sterile body sites can induce invasive conditions that lead to high morbidity and mortality. Therefore, S. pyogenes is pathogenic to humans and animals with its contagious infections. S. pyogenes can transmit through various routes, including direct contact, droplets, nasal discharge, fomites or surfaces contaminated with this bacteria, skin contact with a contaminated lesion, and by oral route from contaminated foods (Vela et al., 2017).

Currently, the increasing antimicrobial resistance (AMR) is becoming the most important problem for both animal and human health as well as the potential zoonotic infection. The problem can challenge the public health system, cause economic loss, and increase the morbidity rate of infected cases and also the mortality rate of the patients who might not be cured by any antibiotic medications (Shuster et al., 2013). The increase of AMR in S. pyogenes has been observed worldwide (Lai et al., 2021). The highest rate of resistance is usually found in erythromycin which was reported in Europe, including Finland, Spain, Italy, Netherlands, Germany, and also the USA (Arvand et al., 2000).

At present, there are many attempts to reduce the usage and for the rational use of antibiotic drugs to treat bacterial infections. Then, the development of alternative agents, including effective natural agents is necessarily required to replace antibiotic drugs. Many studies have addressed the antibiotic activity of plant extracts against the growth of bacteria that could be developed into antibacterial agents or therapeutic drugs (Abiala et al., 2016; Elisha et al., 2017). Marigold petal )Tagetes erecta( has revealed a large amount of flavonoids biologically content, especially for patulitrin that is the dominant active substance in the flavonoids containing anti-inflammatory effect and also effective antibiotic 
activity to destroy bacterial cells (Rhama and Madhavan, 2011; Dasgupta et al., 2012). An earlier study has reviewed the bulbs of red shallot (Allium ascalonicum Hort.) entailing a high level of quercetin can inhibit bacterial growth (Fattorusso et al., 2002). The mulberry (Morus alba L.) extract was found to have bioactive components, such as flavonol quercetin 3-(6-Malonylglucoside) substance which could inhibit both Gram-negative and Gram-positive bacterial pathogens, including Escherichia Coli, Bacillus subtilis, Bacillus cereus, Pseudomonas aeruginosa, and Staphylococcus aureus (Salem et al., 2013; Grajek et al., 2015; Gunjal et al., 2015) and quercetin which could destroy the membranes of bacteria leading to growth inhibitation (Wang et al., 2018). Therefore, the current research aimed to evaluate the antibiotic activity of ethanolic crude extracts from potential Thai medicinal plants, such as red shallot (Allium ascalonicum), mulberry leaves and root (Morus indica) strain Nakhon Ratchasima 60 (Nak 60), and marigold (Tagetes erecta) against Streptococcus pyogenes for the potential of usage as an antibiotic agent to reduce the problem of antibiotic resistance in the future.

\section{MATERIALS AND METHODS}

\section{Ethical approval}

Ethical approval was not required for this research. All experiments and procedures in the current study did not certainly interrupt both humans and animals. All of the experiments and procedures were prepared and processed One Health research unit and Veterinary Public Health (VPH) laboratory room, Faculty of Veterinary Sciences, Mahasarakham University, Maha Sarakham province, Thailand.

\section{Medicinal plant materials}

All Thai medicinal plants in this study were identified, housed, harvested, and collected at Mahasarakham University, Maha Sarakham, Northeastern Thailand. Ethanolic crude extracts were prepared from three Thai medicinal plants as were shown their external characteristic in Table 1 and their antibiotic activities were investigated. The selected medicinal plants which used in this research included root barks and leaves of mulberry (Morus indica) strain Nakhon Ratchasima 60 (Nak 60), marigold petal (Tagetes erecta), and whole onions or bulbs of red shallot (Allium ascalonicum) as shown in Figure 1. All medicinal plants were weighed, washed with purified and distilled water, then, they were dried at room temperature for 5 days. After that, they were chopped into $1 \mathrm{x} 1 \mathrm{~cm}$ pieces and desiccated in a drying oven for 24 hours at $65^{\circ} \mathrm{C}$. The dried medicinal plants were weighed after drying and extracted by soaking with absolute ethanol in a plant-ethanol ratio of 1:5 for 24 hours at room temperature within the cabinet. The medicinal plant extracts were then sieved using a filter paper and concentrated to yield ethanolic crude extracts via evaporation by vacuum rotary evaporator (Heidolph, Germany) at $289 \mathrm{mbar}, 60 \mathrm{rpm}$, and $60^{\circ} \mathrm{C}$ in a water bath as shown in Figure 2 . Each Thai medicinal plant crude extract was then dissolved in dimethyl sulfoxide (DMSO) as solvent before measuring the antibiotic activity test. Each dried plant extracts in this study were used three different concentration tests (low, medium, and high) at $25 \mathrm{mg} / \mathrm{ml}, 50 \mathrm{mg} / \mathrm{ml}$, and $75 \mathrm{mg} / \mathrm{ml}$, respectively.

Table 1. Thai medicinal plants and their part used for antibiotic activity test

\begin{tabular}{lllcc}
\hline Thai medicinal plants & Part used & $\begin{array}{c}\text { Weight before } \\
\text { drying (g) }\end{array}$ & $\begin{array}{c}\text { Weight after } \\
\text { drying (g) }\end{array}$ \\
\hline Common name & Scientific name & Whole onions & 3226 & 557.5 \\
Red shallot & Allium ascalonicum & Root barks & 345.65 & 286 \\
Mulberry & Morus indica & Leaves & 340.45 & 101.78 \\
Marigold & Tagetes erecta & Petals & 557.5 & 201.31 \\
\hline
\end{tabular}

\section{Target bacterial strain}

This study used a reference strain of Streptococcus pyogenes (ATCC19615) as a target microorganism. The bacterial strain was maintained in the Veterinary Public Health Laboratory at the Faculty of Veterinary Sciences, Mahasarakham University, Thiland. S. pyogenes was subcultured from the original bacterial culture, stored at $-20^{\circ} \mathrm{C}$, and streaked on nutrient agar plates (Oxoid, UK) to maintain at $4^{\circ} \mathrm{C}$. It was used to test for antibiotic susceptibility by disc diffusion protocol. S. pyogenes was cultured on tryptone soy agar (Oxoid, UK) in aerobic incubation at $37^{\circ} \mathrm{C}$ for 24 hours. Antibiotic activity testing protocol was processed following the methods for antimicrobial dilution and disk susceptibility testing CLSI guidelines M45 (CLSI, 2017). The S. pyogenes colony had cultured overnight, then, it was suspended in sterile saline water and the suspension has adjusted the turbidity to equal that of a standard value of $1.5 \mathrm{x}$ $10^{8} \mathrm{CFU} / \mathrm{ml}$ by $0.5 \mathrm{McF}$ arland.

\section{Evaluation of antibiotic activity}

Disk diffusion method was processed in triplicate for root barks of mulberry, leaves of mulberry, marigold petal, and whole onions of red shallot ethanolic crude extracts in each concentration. The bacterial suspension was spread onto the surface of the Muller Hinton agar; MHA (Oxiod, UK) that was used to determine the antibiotic activity by sterile cotton swabs. Each dried plant extracts was prepared a concentration at 25,50 , and $75 \mathrm{mg} / \mathrm{mL}$ stock solution in DMSO. Wells which were used to place the medicinal plant extracts testing were cut into MHA. The volume of stock solutions 
about $5 \mu \mathrm{l}$ in each concentration was loaded to the wells in MHA plates which the target bacterial strain was spread along with representative antibiotic drugs as selected antibiotic assay discs including erythromycin and ceftriaxone (Oxoid, UK) which used as the positive control, then incubated the plates in aerobic incubation for 24 hours at $35^{\circ} \mathrm{C}$ together with DMSO which was utilized as the solvent control or negative control in this trial. The zone of the inhibition diameters in each plate was interpreted following the recommendation of CLSI guidelines M100 (CLSI, 2020).

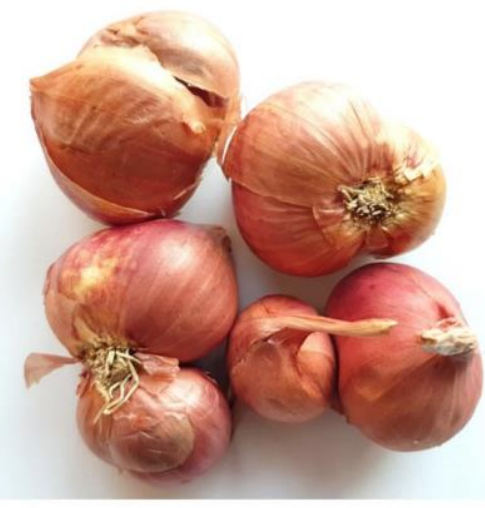

A
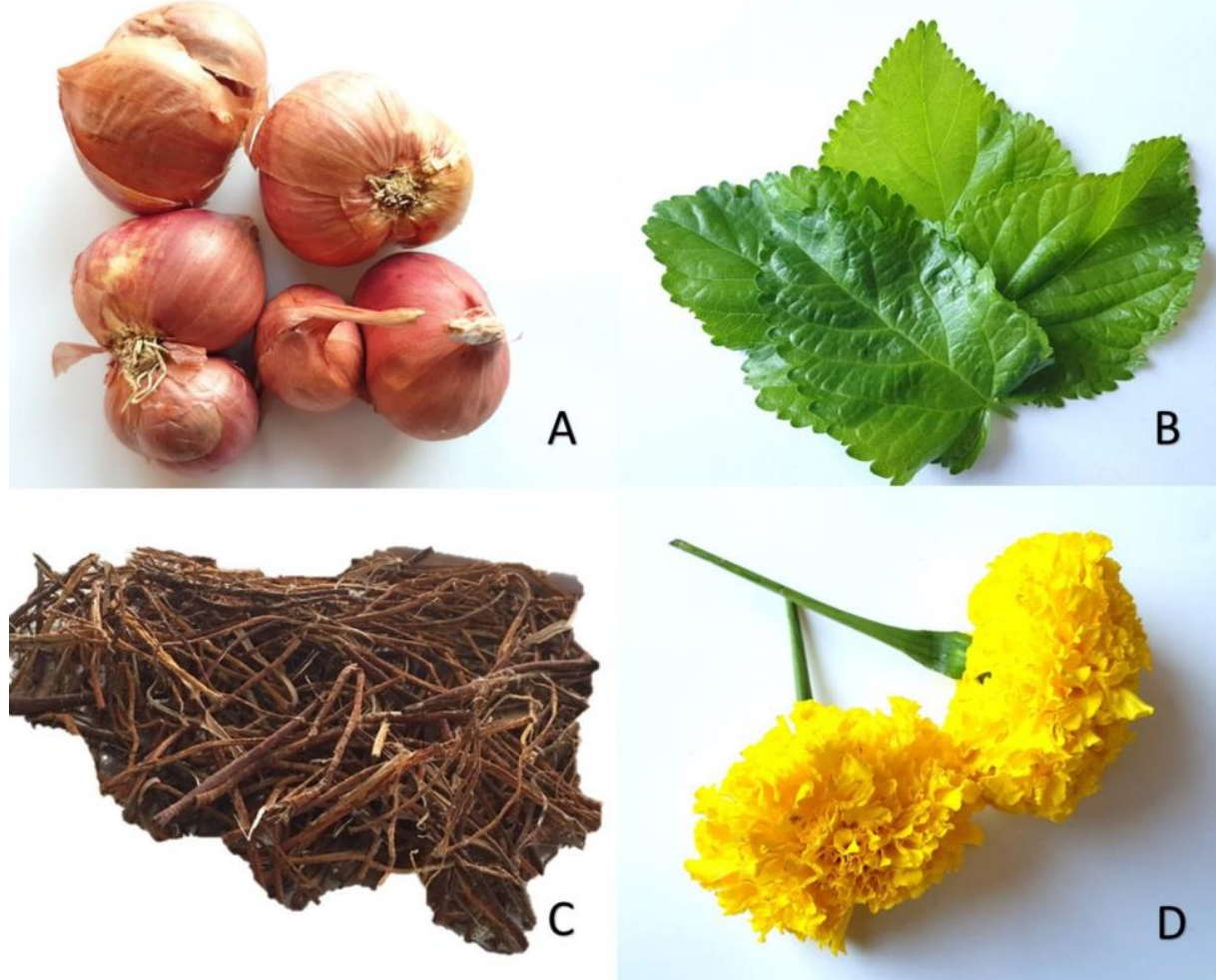

Figure 1. Thai medicinal plants used in the experiment, Whole onions of red shallot (A), Mulberry leaves (B), Root barks of mulberry (C), Petals of marigold (D)

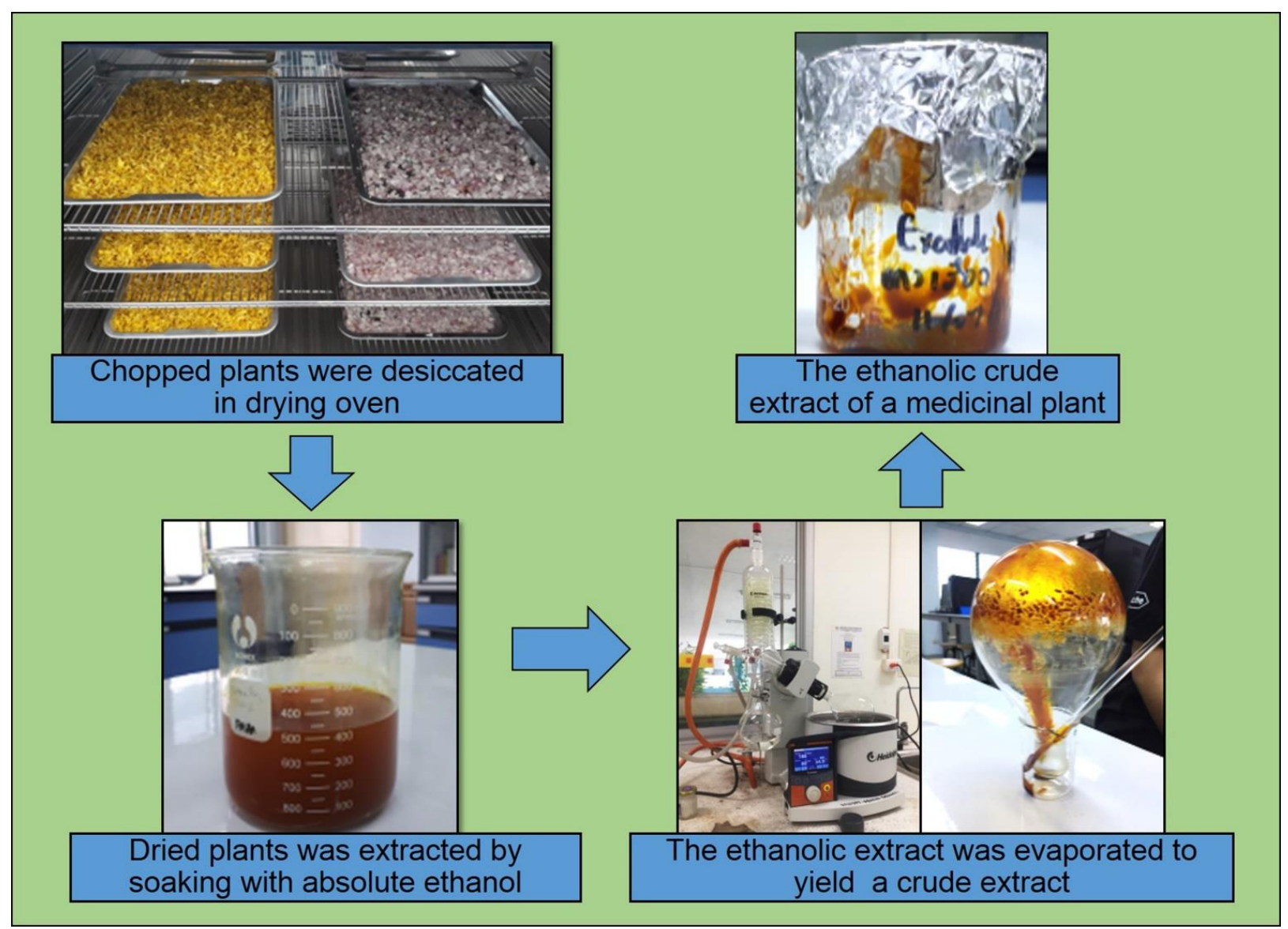

Figure 2. The extraction methods of Thai medicinal plants 


\section{Statistical analysis}

The experimental data were statistically analyzed using differentiation of disk diffusion results by descriptive statistics analysis and one-way analysis of variance (ANOVA) and the least significant difference (LSD) post hoc tests at 95\% confidence level. The significance statistical difference was set at $p<0.05$. The IBM SPSS statistic version 21.0 was used for analysis .

\section{RESULTS}

The experimental result from the antibiotic activity trial for inhibiting the growth of $S$. pyogenes by the ethanolic crude extracts of Thai medicinal plants is demonstrated in Table 2 .Ethanolic crude extracts of red shallot and mulberry showed the antibiotic activities on the reference strain of $S$. pyogenes. From the result of inhibition zone performed by the lowest concentration at $25 \mathrm{mg} / \mathrm{ml}$, the average diameters of inhibition zone of whole onions of red shallot extract, root barks of mulberry extract, leaves of mulberry extract, and marigold petal extract were 7.1, 5.17, 5.33, and 2 mm, respectively. At $50 \mathrm{mg} / \mathrm{ml}$ concentration, the average diameters of the inhibition zone were 7.83, 6.17, 6.67, and $2.5 \mathrm{~mm}$, respectively. At least, the average diameters of the inhibition zone of the highest concentration at $75 \mathrm{mg} / \mathrm{ml}$ were $8.67,7,7.83$, and $3 \mathrm{~mm}$, respectively.

Thai medicinal plant extracts comprising red shallot, root bark, and leaves of mulberry showed good antibiotic activity against $S$. pyogenes, while marigold extract rarely had antibiotic activity. Red shallot ethanolic extracts appeared the most antibiotic activity following by the crude extract of mulberry leaves and root bark of mulberry extract, respectively. The inhibition zones of erythromycin and ceftriaxone which were used as the positive control in this trial were $15.67 \mathrm{~mm}$ and $24.42 \mathrm{~mm}$ in diameter, respectively. There were statistically significant differences among the four categories of Thai medicinal plant extracts in all concentration tests when analyzed through one-way ANOVA and the least significant difference (LSD) post hoc tests at 95\% confidence level. The obtained results from LSD post hoc test indicated that the ethanolic extracts of red shallot bulbs were the most effective against $S$. pyogenes, while the ethanolic extracts of marigold showed the lowermost antimicrobial activity at all concentration tests.

Table 2. Antibiotic activity of Thai medicinal plant ethanolic crude extracts demonstrated as the diameter of inhibition zone

\begin{tabular}{|c|c|c|c|}
\hline \multirow{3}{*}{ Thai medicinal plants extract } & \multicolumn{3}{|c|}{ Zone of inhibition diameter (mm) } \\
\hline & \multicolumn{3}{|c|}{ Plant extracts concentration )mg/ml) } \\
\hline & 25 & $\mathbf{5 0}$ & 75 \\
\hline \multirow{3}{*}{ Red shallot } & 7 & 7.5 & 8.5 \\
\hline & 7.5 & 8 & 8.5 \\
\hline & 7 & 8 & 9 \\
\hline Average & 7.16 & 7.83 & 8.67 \\
\hline \multirow{3}{*}{ Mulberry (root bark) } & 5 & 6 & 7.5 \\
\hline & 5 & 6 & 6.5 \\
\hline & 5.5 & 6.5 & 7 \\
\hline Average & 5.17 & 6.17 & 7 \\
\hline \multirow{3}{*}{ Mulberry (leaves) } & 6 & 7 & 8 \\
\hline & 5 & 6 & 7.5 \\
\hline & 5 & 7 & 8 \\
\hline Average & 5.33 & 6.67 & 7.83 \\
\hline \multirow{3}{*}{ Marigold } & 2 & 2.5 & 3 \\
\hline & 2.5 & 3 & 3.5 \\
\hline & 1.5 & 2 & 2.5 \\
\hline Average & 2 & 2.5 & 3 \\
\hline
\end{tabular}

\section{DISCUSSION}

The outcomes of the study revealed the potential antibiotic activity derived from ethanolic crude extracts of Thai medicinal plants comprising red shallot, mulberry leaves, and mulberry roots strain Nakhon Ratchasima 60 (Nak 60) inhibiting the growth of $S$. pyogenes. Ethanolic crude extracts of bulbs or whole onions part of red shallot expressed the highest potential inhibitory activity against $S$. pyogenes which is consistent with a previous study from Mekvimol et al. (2020) that mentioned the high antibiotic activity of red shallot and mulberry leaves extracts against the growth of Grampositive bacteria, such as Streptococcus agalactiae. The findings of the current research indicated that the bulbs or whole 
onions part of red shallot and the leaves and rook barks part of mulberry ethanolic crude extracts have the possibility to inhibit the growth of $S$. pyogenes in all concentrations. Some previous studies reported that the shallot bulbs and mulberry leaves contain a high level of active phenolic compound which demonstrated to have antimicrobial activities, including flavonoid substance which can inhibit the growth of bacteria (Butkhup et al., 2013; Mozin et al., 2015). The major active ingredient of flavonoid substances from these herb extracts is quercetin with a bactericidal effect by demolishing bacterial cell membranes (Mozin et al., 2015). Therefore, this result is consistent with many previous studies indicating that quercetin was a crucial bioactive compound and plays a role in inhibiting Gram-positive and Gram-negative bacteria by prohibiting the activity of extracellular proteins (Koo and Jeon, 2009; Mozin et al., 2015; Fredotović et al., 2021). Nevertheless, some reports revealed that quercetin could not inhibit the growth of some Gramnegative organisms include E. coli and Salmonella typhi (Souza et al., 2010; Mozin et al., 2015). The bioactivity compounds of red shallot and mulberry which were revealed the potential antibiotic activity on S. pyogenes were likely more effective to inhibit bacterial growth, while ethanolic extract of marigold seemed to have no effect on the bacterial growth. The in vitro study of antibiotic activity from Thai medicinal plant extracts is a crucial phase for the alternative treatment strategy as surrogate antibacterial agents replacing antibiotic drugs for several bacterial pathogens, including $S$. pyogenes. The findings of the current in vitro study can be well used for alternative medicine. These medicinal plants in urban communities can be developed into therapeutic drugs as plant-based antimicrobial agents. This evidence is in accordance with many previous studies that revealed the success of herbal medicine in curing bacterial infectious diseases (Palombo, 2011; Abiala et al., 2016; Elisha et al., 2017). More than that, the current research seems to be the first investigation that discovered ethanolic crude extracts from various Thai medicinal plants, including whole onions of red shallot, root bark, and leaves of mulberry had antibiotic activity against the growth of S. pyogenes.

\section{CONCLUSION}

The current in vitro study revealed that red shallot (Allium ascalonicum), leaves part and root barks part of mulberry (Morus indica) strain Nakhon Ratchasima 60 (Nak 60) ethanolic extracts expressed the antibiotic activity against $S$. pyogenes. Thus, the future development of red shallot and mulberry leaves ethanolic extracts as an alternative treatment for $S$. pyogenes infections in both humans and animals are recommended for resolving the antimicrobial resistance in the prospect. Ethanolic crude extract of red shallot exhibited strong activity against S. pyogenes reference strain ATCC19615. Further investigation should be aimed to analyze the quantity of active ingredients and action mode of these plant extracts against bacterial clinical strains. It would be interesting to evaluate in vivo trial for developing and applying these medicinal plants as natural therapeutic products for both humans and animals for medical and veterinary use.

\section{DECLARATIONS}

\section{Competing interest}

The authors declare that they have no competing interests.

\section{Authors' contribution}

Natapol Pumipuntu designed and supervised the research project, supported in the experimental study and data analysis. Tanawadee Mekvimol, Chayanit Chaipunna, and Gannika Poonthong designed the research experiment and collected the data. All authors interpreted the data, wrote the manuscript, and approved the final version.

\section{Ethical consideration}

Ethical issues (including plagiarism, consent to publish, misconduct, data fabrication and/or falsification, double publication and/or submission, and redundancy) have been checked by all the authors.

\section{Acknowledgments}

This research project was financially supported by Mahasarakham University (Fast Track 2021). The authors are grateful to the Faculty of Veterinary Sciences, Mahasarakham University for the use of the laboratory to carry out this experiment. The authors would like to thank Asst. Prof. Dr. Prasoborn Rinthong, Faculty of Pharmacy, Mahasarakham University for her advice. All authors are also grateful to Miss Thamonphan Wimonsrinarachai, a veterinary student at the Faculty of Veterinary Sciences, Mahasarakham University for the graphical abstract design and illustration.

\section{REFERENCES}

Abiala M, Olayiwola J, Babatunde O, Aiyelaagbe O, and Akinyemi S (2016). Evaluation of therapeutic potentials of plant extracts against poultry bacteria threatening public health. BMC Complementary and Alternative Medicine, 16(1): 417. DOI: https://www.doi.org/10.1186/s12906-016-1399-z 
Arvand M, Hoeck M, Hahn H, and Wagner J (2000). Antimicrobial resistance in Streptococcus pyogenes isolates in Berlin. Journal of Antimicrobial Chemotherapy, 46(4): 621-624. DOI: https://www.doi.org/10.1093/jac/46.4.621

Butkhup L, Samappito W, and Samappito S (2013). Phenolic composition and antioxidant activity of white mulberry (Morus alba L.) fruits. International Journal of Food Science and Technology, 48: 934-940. DOI: https://www.doi.org/10.1111/ijfs.12044

Clinical and Laboratory Standards Institute (CLSI) (2017). Methods for antimicrobial dilution and disk susceptibility testing of infrequently isolated or fastidious bacteria. $3^{\text {rd }}$ ed. CLSI guideline M45. Wayne, PA: Clinical and Laboratory Standards Institute, 5(7): 7-8. Available at: https://goums.ac.ir/files/deputy_treat/md_labs_ef39a/files/CLSI-M45ed3e-2018(1).pdf

Clinical and Laboratory Standards Institute (CLSI) (2020). Performance standards for antibiotic susceptibility testing. $31^{\text {st }}$ ed. Informational supplement CLSI document M100. Wayne, PA: clinical and laboratory standards institute, 40(1): 88-94. Available at: https://www.nih.org.pk/wp-content/uploads/2021/02/CLSI-2020.pdf

Cunningham MW (2000). Pathogenesis of group a streptococcal infections. Clinical Microbiology Reviews, 13(3): 470-511. DOI: https://www.doi.org/10.1128/cmr.13.3.470-511.2000

Dasgupta N, Ranjan S, Saha P, Jain R, Malhotra S, and Saleh MAAM (2012). Antibiotic activity of leaf extract of Mexican marigold (Tagetes erecta) against different gram positive and gram negative bacterial strains. Journal of Pharmacy Research, 5(8): 42014203. Available at: http://iprsolutions.info/files/final-file-57944be92c4dd0.83730986.pdf

Elisha IL, Botha FS, McGaw LJ, and Eloff JN (2017). The antibacterial activity of extracts of nine plant species with good activity against Escherichia coli against five other bacteria and cytotoxicity of extracts. BMC Complementary and Alternative Medicine, 17(1): 133. DOI: https://www.doi.org/10.1186/s12906-017-1645-z

Fattorusso E, Iorizzi M, Lanzotti V, and Taglialatela-Scafati O (2002). Chemical composition of shallot (Allium ascalonicum Hort.). Journal of Agricultureal and Food Chemistry, 50(20): 5686-5690. DOI: https://www.doi.org/10.1021/jf020396t

Fredotović Ž, Puizina J, Nazlić M, Maravić A, Ljubenkov I, Soldo B, Vuko E, and Bajić D (2021). Phytochemical characterization and screening of antioxidant, antimicrobial and antiproliferative properties of Allium $\times$ cornutum Clementi and two varieties of Allium cepa L. peel extracts. Plants, 10(5): 832. DOI: https://www.doi.org/10.3390/plants10050832

Gunjal S, Ankola AV, and Bhat K (2015). In vitro antibiotic activity of ethanolic extract of Morus alba leaf against periodontal pathogens. Indian Journal of Dental Research, 26(5): 533-536. Available at: https://www.ijdr.in/article.asp?issn=09709290; year=2015; volume=26;issue=5; spage=533; epage $=536$; aulast $=$ Gunjal

Grajek K, Wawro A, and Kokocha D (2015). Bioactivity of Morus alba L. extracts - an overview. International Journal of Pharmaceutical Sciences and Research, 6: 3110-3122. Available at: https://ijpsr.com/bft-article/bioactivity-of-morus-alba-lextracts-an-overview/?view=fulltext

Koo H, and Jeon J G (2009). Naturally occurring molecules as alternative therapeutic agents against cariogenic biofilms. Advances in Dental Research, 21(1): 63-68. DOI: https://www.doi.org/10.1177/0895937409335629

Lai CC, Chen SY, Ko WC, and Hsueh PR (2021). Increased antimicrobial resistance during the COVID-19 pandemic. International Journal of Antimicrobial Agents, 57(4): 106324. DOI: https://www.doi.org/10.1016/j.ijantimicag.2021.106324

Mekvimol T, Poonthong G, Chaipunna C, and Pumipuntu N (2020). Antimicrobial activity of marigold (Tagetes erecta), mulberry (Morus indica), and red shallot (Allium ascalonicum) extracts against Streptococcus agalactiae. International Journal of One Health, 6(1): 56-60. DOI: https://www.doi.org/10.14202/IJOH.2020.56-60

Mozin S, Rosyidi D, Sjofjan O, and Widodo E (2015). The effect of shallot (Allium ascalonicum L.) by-product as an antibiotic and alternative phytobiotic on characteristics of small intestine of broiler. Livestock Research for Rural Development, 27(4): Article \#78. Available at: http://www.lrrd.org/lrrd27/4/mozi27078.htm

Palombo E (2011). Traditional medicinal plant extracts and natural products with activity against oral bacteria: potential application in the prevention and treatment of oral diseases. Evidence-based Complementary and Alternative Medicine, Article ID 680354. DOI: https://www.doi.org/10.1093/ecam/nep067

Rhama S, and Madhavan S (2011). Antibiotic activity of the flavonoid, patulitrin isolated from flowers of Tagetes erecta L. International Journal of Pharm Tech Research, 3(3): 1407-1409. Available at: https://www.sphinxsai.com/Vol.3No.3/pharm/pdf/PT=30(1407-1409)JS11.pdf

Salem M, Aly H, Gohar Y, and El-Sayed A (2013). Biological activity of extracts from Morus alba L., Albizzia lebbeck (L.) Benth and Casuarina glauca Sieber against the growth of some pathogenic bacteria. International Journal of Agriculture Food Science and Technology, 2(1): 9-22. DOI: https://www.doi.org/10.24102/ijafr.v2i1.122

Shuster KA, Hish GA, Selles LA, Chowdhury MA, Wiggins RC, Dysko RC, and Bergin IL (2013). Naturally occurring disseminated group B streptococcus infections in postnatal rats. Comparative Medicine, 63(1): 55-61. Available at: https://www.ncbi.nlm.nih.gov/pmc/articles/PMC3567377/

Souza LD, Wahidulla S, and Devi P (2010). Antibacterial phenolics from the Mangrove Lumnitzera racemosa. Indian Journal of Marine Sciences, 39(2): 294-298. Available at: http://nopr.niscair.res.in/handle/123456789/10027

Spellerberg BC (2016). Laboratory Diagnosis of Streptococcus pyogenes (group A streptococci). Streptococcus pyogenes : Basic biology to clinical manifestations. Oklahoma City, pp. 10-11. Available at: https://www.ncbi.nlm.nih.gov/books/NBK343617/

Vela AI, Villalon P, Saez-Nieto JA, Chacon G, Dominguez L, and Fernandez-Garayzabal JF (2017). Characterization of Streptococcus pyogenes from Animal Clinical Specimens, Spain. Emerging Infectious Diseases, 23(12): 2013-2016. DOI: https://www.doi.org/10.3201/eid2312.151146

Wang S, Yao J, Zhou B, Yang J, Chaudry MT, Wang M, Xiao F, Li Y, and Yin W (2018). Bacteriostatic effect of quercetin as an antibiotic alternative in vivo and its antibiotic mechanism in vitro. Journal of Food Protection, 81(1): 68-78. DOI: https://www.doi.org/10.4315/0362-028X.JFP-17-214 